\title{
Research on Collaborative Development Mechanism of Logistics Service in Transformation of Entity Retail Enterprises
}

\author{
Bin Zhao, a , Yanqiu Sun ${ }^{1, b}$ \\ ${ }^{1}$ School of Management, Tianjin University of Technology, Tianjin 300384, China \\ avickyly510@163.com, b1334940164@qq.com
}

Keywords: retail industry; logistics industry; collaborative development; mechanism

\begin{abstract}
In recent years, the online retail industry has been booming, and traditional retail companies are being eroded by online businesses. It is extremely urgent for traditional retail companies to transform into modern retail which develop online and offline businesses together. The development of the online retail industry has provided a broad space for growth for the logistics industry. At the same time, the logistics industry has supported and promoted the development of online retail industry, which are interdependent, mutually supportive, and complementary, so the coordinated development of them is inevitable. However, as the online retail industry and the logistics industry have not yet formed a unified and clear coordinated development mechanism, which seriously restricts the coordinated development of the two industries. Based on the domestic and foreign relevant literature, this research qualitatively analyzes the current situation of collaborative development. Then, it proposes the problems of the collaborative development mechanism of logistics and retail industry; Finally, this paper provides relevant recommendations to the coordinated development of the online retail industry and the logistics industry.
\end{abstract}

\section{The Transformation of Retail Industry}

With the widespread popularity of the Internet, e-commerce has occupied the market rapidly due to its advantages of being free from time and place restrictions, convenience and promptness. It has greatly impacted the traditional retail industry's position in the market and posed a great challenge to the development of traditional retail industry. Therefore, the traditional retail industry must adapt to the requirements of the development of the times, satisfy consumers' ever-changing shopping needs, constantly adjust their own marketing strategies, actively use the e-commerce platform, combine their own advantages and characteristics, and unshakably transform their business model. Only that can we maintain the sustained and healthy development of our company. In recent years, the rapid development of China's online retail industry has become a highlight of the national economy. In 2011, the scale of China's online retail has reached 800 billion yuan, a year-on-year growth of $56.0 \%$. In 2015, the transaction volume of China's online retail market reached 382.85 billion yuan, a year-on-year increase of 35.7\%, which was more than four times that of 2011. By 2017, the online retail sales growth was 32.2\% year-on-year, an increase of 6 percentage points over the previous year. Among them, the online retail value of physical goods reached 5.48 trillion yuan, an increase of $28 \%$, accounting for $15 \%$ of the total retail sales of social consumer goods, up 2.4 percentage points over the previous year. The contribution rate to the growth of total retail sales of consumer goods was $37.9 \%$, an increase of 7.6 percentage points over the previous year. The role of online retail in driving consumption has been further enhanced.

\section{The Coordinated Development Mechanism of Logistics Services and Retail Industry}

In recent years, the online retail industry has been working more closely with logistics companies, under the strong support of logistics companies, the online retail industry has made major breakthroughs and its position in the retail industry has been increasing. At the same time, driven by the online retail industry, the logistics business's traffic volume and income have 
continuously increased, and the quality of service have also made significant progress. These two industries rely on each other and promote each other, and they have broad prospects for coordinated development. The online retail industry is an important part of e-commerce, and logistics companies are an important part of the modern service industry. Under the dual background of China's vigorous promotion of information technology development strategy and service industry development strategy, the coordinated development of the two industries is full of opportunities. We discuss the coordinated development of the two industries in the following three aspects:

\subsection{Organizational coordination}

(1) Selection and construction of cooperative subject. The choice of collaborative subjects is the first issue when constructing a cooperative organization. Online retail companies and logistics companies need to choose a good partner if they want to establish a solid strategic alliance relationship and make an efficient and effective cooperation. The main measure factors of cooperative subject includes factors such as willingness factors, energy factors, and compatibility factors and so on.

(2) Construction of collaborative organizations. Firstly, to determine the goal of collaborative management, supply chain collaboration management plays a crucial role in the survival and development of online retail companies and logistics companies. Secondly, it is necessary for the cooperative subject to adjust their internal organizational structure to form a coordinated internal supply chain, to ensure seamless cooperation between enterprises. Finally, the mutual trust between the cooperative companies in the supply chain is an important factor which will influence the collaborative performance. Trust can reduce the contractual arrangements or other forms of transaction integration, so it can reduce transaction costs and bring a competitive advantage.

(3) The operation and maintenance of the cooperative organization. Both online retail companies and logistics companies need to use market information to make overall predictions. Online retail companies not only have powerful data mining and data analysis capabilities, but also are closer to the market, so they can more accurately predict market demand. Otherwise, the collaborative supply chain formed by online retail companies and logistics companies is a dynamic system. After a period of continuous operation, encountering problems is inevitable, Certainty requiring continuous maintenance and improvement of collaborative organizations.

\subsection{Resource cooperation}

Enterprise resources are the foundation of enterprise value. Enterprise resource coordination is an important part of enterprise collaboration.

(1) Joint planning of human resources. China's logistics companies generally have problems such as low level of cultural quality, high mobility, and lack of experience in the operation of online retail express, This directly restricts the operational capacity of logistics companies. The joint planning of human resources within the complex system will help foster excellent personnel who are familiar with the online retail express delivery, and will be able to improve the express delivery capabilities. In the training of professionals, both internal training and external training of the system can be used.

(2) Hardware resource cooperation. Hardware resources are the material support for collaborative supply chain's operation. Hardware resource sharing is one of the motivation for the online retail companies and logistics companies to implement a collaborative strategy. Regardless of whether the shared resources are owned by an independent company or shared by both companies, it is necessary to clearly define the corresponding rights and obligations. For example, it is necessary to negotiate and determine in advance about maintenance, repair, depreciation, and other problems and the solutions to the damages of the sharing resources.

\subsection{Information cooperation}

Information is an important method and means to ensure collaborative implementation. Therefore, after the analysis of the collaborative strategy of the composite system organization and resource coordination, it is necessary to establish an information strategy that is compatible with it 
to ensure the realization of collaboration. The primary content of decision-making at the strategic level of information is based on the strategic objectives of the collaborative supply chain, planning the system's information construction goals and the construction framework under this goal. Based on the information strategy of collaborative supply chain, online retail companies and logistics companies should begin to strengthen the internal information system construction and the interconnection of each other. They must also negotiate and confirm the specific content of sharing. Order information is the core data of online retail companies and is the source of corporate profits. Therefore, online retail companies pay great attention to protect customers' information, but sharing order information is the basis for cooperation between online retail companies and logistics companies. The sharing of information not only enables online retail companies to grasp the location of commodity, sign on or not, and can also use this information to evaluate the service quality of logistics companies; it also facilitates consumers to keep eyes on the progress of commodity and encourage logistics companies to improve service quality themselves.

\section{Problems in the Collaborative Development}

\subsection{The low degree of coordinated development}

In recent years, although the online retail industry has been working more closely with logistics companies and it's scope has been continuously expanded and the level has been continuously improved. As far as the current situation is concerned, the degree of coordinated development between the two industries is not high, and it is still at the stage of simple courier service demand and supply. The basic reason is that there is no close supply chain partnership between online retail companies and logistics companies, and no effective collaborative development mechanism has been established between them. The specific reasons are as follows: First, online retail enterprises are "light asset" enterprises, while logistics enterprises are "heavy assets" enterprises. There are different asset attributes, different corporate cultures and differences in employee quality between them, which seriously undermines the synergy between them. Second, there doesn't has a case in which the online retail companies and logistics companies have collaborated to develop effectively, the collaborative development path is not clear. Third, the online retail companies and logistics companies maximize their interests individually, lacking a unified and reasonable income distribution mechanism.

\subsection{Problems in the development of retail and logistics companies}

In addition to the low degree of synergy between the two industries, online retailing and logistics companies also have many problems in their respective development processes, This also restricts the coordinated development of the two industries.

(1) Problems in the online retail industry. In recent years, complaints from online retail consumers have been rising. According to data released by People's Daily, $71.4 \%$ of online retailers have had an unpleasant shopping experience in the past year. According to the data released by the China Consumers Association, consumer associations at all levels accepted a total of 30,518 complaints of online retail users in 2015 , accounting for $53.6 \%$ of the complaints for sales services. The complaints mainly focused on the false publicity of online retail enterprises, problems with product quality, unsatisfactory after-sales services, slow delivery, and damaged express parcels.

(2) Problems in the logistics industry. The development of logistics logistics enterprises in China faces many problems. First, the technical equipment is backward, the number of courier-operated aircraft is less than 100 , and the processing of sub-blocks relies on labor; second, the service level of express delivery companies is not high, and the capacity is insufficient. It still stays at the stage of low-price homogenous competition; and thirdly, express delivery companies. There are policy bottlenecks in the construction land, vehicles entering the city, trunk transportation, etc. Fourth, domestic express delivery companies are generally smaller in scale and weaker in strength than foreign-funded enterprises, and most have not yet been formed; fifth, the logistics company's security situation and supervision Work is also facing a severe test. 


\section{Suggestions for the Collaborative Development of Logistics Services in the Innovation Transformation of Retail Enterprises}

\subsection{Develop information technology}

The development and widespread application of network technologies, communication technologies, and electronic computers not only made it possible for cross-enterprise and cross-regional collaboration between online retail and logistics companies, but also became a driving force for collaboration between the two industries. With the continuous advancement of information technology, the degree of information sharing between online retail companies and express delivery companies is getting higher and higher, and information synergy effects are becoming more and more obvious. This undoubtedly promotes the coordinated development of the two industries. In the process of coordinated development of the two industries, the universal application of the software under play plays an important role.

\subsection{Strengthen information sharing}

The employees of online retail companies and express delivery companies have accumulated rich experience in long-term work practices and have a deep understanding of the operating laws of their respective industries. After the online retail companies and express delivery companies implement a coordinated strategy, each employee can share the operating experience and operating rules of the cooperative company. In addition, the sharing of knowledge among enterprises will inevitably produce a synergistic effect of $1+1>2$, which is conducive to cultivating team spirit in sharing, and will help improve the responsibilities and integrity of employees. Enterprises in the knowledge of information sharing in the organization of continuous learning, you can barely absorb the knowledge and innovation capabilities, thereby enhancing the competitiveness, so the sharing of knowledge and knowledge is the synergy of online retail companies and express delivery companies.

\subsection{Increase policy support}

The government should encourage and support express delivery companies in the country's logistics node cities, online retail demonstration cities, and the overlap between the two regions to establish express mail processing in China, aviation distribution center, transport is critical for the development of express delivery companies. In order to meet the express delivery needs of the online retail industry, the government should support express delivery companies to significantly increase the level of standardization, information, and automation in such aspects as rollovers, dispatching, transit transport, and swamping. The government can strengthen inter-departmental coordination, study and formulate urban distribution management methods, vehicle standards, and environmental models, and take into account the contents of express delivery vehicles.

\subsection{Strengthen market supervision and maintain market order}

In order to enhance the consumer's trust, the government should vigorously guide express delivery companies and online retailers to strengthen the credit system, strictly implement the credit management system, and establish a good corporate reputation. The specific implementation method is to organize the postal administration bureau or the express delivery association to carry out the grade assessment of express delivery enterprises nationwide and implement differentiated management strategies according to the grades assessed; to organize various levels of economic and trade commissions or Chinese e-commerce research, etc. Conduct online credit evaluation for online retail enterprises, and regularly publish this credit rating information to the public. It is also necessary to increase the mutual recognition of the credit evaluation of express delivery companies and online retail enterprises, and improve the exchange and sharing mechanism of credit information resources among industry management departments. 


\section{References}

[1] Chen Jun. Discussion on the Experience Marketing Model of Traditional Retail Stores under E-commerce Environment[J]. Business Economics Research, 2015(1)

[2] Wang Kefu. Application of Precision Marketing in Retail Industry from the Perspective of Big Data[J]. Business Economics Research, 2015(6)

[3] Wu Yanyun. Research on the coordinative degree of port logistics and regional economy in Suining coastal economic belt [D], Dalian: Dalian Maritime University 2012.

[4] Huang Xiaowei, He Mingsheng. Construction and application of collaborative degree measurement model for supply chain resources[J]. Harbin Institute of Technology, 2010, (1):110-115.

[5] Zhang Lingrong. Research on supply chain collaborative evaluation model [D]. Dalian: Dalian University of Technology, 2011.

[6] Wang Wei, Chen Weicheng, Huang Li, et al. Research on the coordination of regional logistics and regional economy based on synergetic theory[J]. Chinese Market, 2010, 32(15): 6-8.

[7] Li Songqing, Su Bing. The grey relational analysis of the linkage development of Guangdong manufacturing and logistics industry [J]. Chinese collective economy, 2009, 68 (15): 104-105.

[8] Wang Guoshun, Qiu Zihao. The Comparison of Retail Business Online and Physical Retailing and Cooperative Path Selection[J]. Finance and Economics Theory and Practice, 2012(7).

[9] Maity M, Doss M. Consumer Decision-Making across Modern and Traditional Channels: E-Commerce, M-Commerce, In-Store. Decision Support Systems,2014

[10] Huang L, Zhang J, Liu H, eta. The effect of online and offline word-of-mouth on new product diffusion. Journal of Strategic Marketing,2014: 1-13

[11] Pookulangara S, Hawley J, Xiao G. Explaining multi-channel consumer's channel-migration intention using theory of reasoned action. International Journal of Retail \& Distribution Management,2011,39(3): 183-202

[12] Chiu H C, Hsieh Y C, Roan J, eta. The challenge for multichannel services: Cross-channel free-riding behavior. Electronic Commerce Research and Applications, 2011,10(2):268-277 